\title{
Use of balloon expandable transcatheter valves for valve-in-valve implantation in patients with degenerative stentless aortic bioprostheses: Technical considerations and results
}

\author{
Vinayak Bapat, FRCS, CTh, William Davies, FRCP, Rizwan Attia, MRCS, Jane Hancock, FRCP, \\ Kirsty Bolter, MSc, Christopher Young, FRCS, CTh, Simon Redwood, FRCP, and Martyn Thomas, FRCP
}

\begin{abstract}
Objective: Transcatheter valve-in-valve is an accepted treatment in high-risk patients with degenerative stented bioprostheses in the aortic position. Experience in treating stentless valves is, however, limited. Our aim was to determine the feasibility and single-center outcome of balloon expandable SAPIEN valve placement in degenerated stentless aortic valve bioprostheses.
\end{abstract}

\begin{abstract}
Methods: From February 2010 to January 2014, 10 patients with failing stentless bioprostheses underwent transcatheter aortic valve implantation using the Edwards SAPIEN transcatheter heart valve (SAPIEN, SAPIEN XT, and SAPIEN 3) at our institution. Seven patients had valve failure due to regurgitation and three to stenosis. The mean age was $73.3 \pm 15.0$ years. The mean logistic EuroSCORE was $31.8 \pm 20.3$, and the Society of Thoracic Surgeons score was $7.6 \pm 5.4$.

Results: Technical success was achieved in 9 of 10 patients. One patient required immediate placement of a second valve owing to low placement of the first. Two intraoperative complications developed that needed additional procedures. One patient underwent immediate repair of a right ventricular perforation from a pacing lead, the other, reexploration for epicardial bleeding. No deaths occurred. The median length of stay was 8.5 days (range, 3-44). The mean follow-up was 8.1 months (range, 1-21). No late reoperations or reinterventions were required.
\end{abstract}

Conclusions: Transcatheter aortic valve implantation after previous stentless aortic valve replacement is technically demanding but a safe and feasible approach. The early results were excellent, with consistent improvement in hemodynamics. Prospective long-term follow-up in larger series is needed to evaluate this technique further. (J Thorac Cardiovasc Surg 2014;148:917-24)

Transcatheter aortic valve implantation (TAVI) has emerged as a viable treatment modality for patients with severe native aortic valve stenosis and multiple comorbidities that would typically preclude them from surgery. ${ }^{1,2}$ The expanding indications have led to the use of transcatheter heart valves (THVs) to treat stented bioprosthetic aortic valves that are failing owing to either stenosis or regurgitation.,

During a valve-in-valve (VIV) procedure with a stented bioprosthesis, the sewing ring and frame provide an anchor

\footnotetext{
From the Department of Cardiovascular Surgery and Cardiology, St Thomas' Hospital, London, United Kingdom.

Disclosures: Vinayak Bapat is a consultant for Edwards Lifesciences, St Jude Medical, and Medtronic Inc. Christopher Young and Martyn Thomas are consultants for Edwards Lifesciences. All other authors have nothing to disclose with regard to commercial support.

Read at the 94th Annual Meeting of The American Association for Thoracic Surgery, Toronto, Ontario, Canada, April 26-30, 2014.

Received for publication March 17, 2014; revisions received April 26, 2014; accepted for publication May 5, 2014; available ahead of print July 16, 2014.

Address for reprints: Vinayak Bapat, FRCS, CTh, Department of Cardiovascular Surgery and Cardiology, St Thomas' Hospital, 6th Floor, East Wing, Westminster Bridge Rd, London SE1 7EH, United Kingdom (E-mail: vnbapat@yahoo.com). $0022-5223 / \$ 36.00$

Copyright (c) 2014 by The American Association for Thoracic Surgery http://dx.doi.org/10.1016/j.jtcvs.2014.05.029
}

for the THV; hence, the procedure can be performed with relative ease. ${ }^{5,6}$ In stentless valves, the lack of a stent frame and sewing ring results in the absence of radiopaque markers to allow VIV positioning. Moreover, different sewing techniques and the proximity to the coronary ostia can make the VIV procedure challenging. ${ }^{7}$ Furthermore, the mechanism of failure of this valve type has typically been cusp perforation or prolapse leading to regurgitation, which could make locating the annular plane for correct positioning difficult. ${ }^{7-9}$ These factors can amount to a greater incidence of malposition, embolization, and coronary obstruction during VIV compared with the VIV procedure in the stented bioprosthesis. ${ }^{9}$ Choosing the correct type and size of the THV device is also important. THVs are available either as balloon expandable or selfexpandable valves. There is currently a stronger inclination to use the self-expandable THV with a nitinol frame when performing VIV in a stentless bioprosthesis.

We report the feasibility of implanting a balloon expandable THV, the successful early outcomes of VIV for degenerated stentless biological aortic valve prostheses, and discuss the technical considerations in planning and performing such cases. 


$$
\begin{aligned}
& \text { Abbreviations and Acronyms } \\
& \text { ID }=\text { internal diameter } \\
& \text { TA }=\text { transapical } \\
& \text { TAVI }=\text { transcatheter aortic valve implantation } \\
& \text { TEE }=\text { transesophageal echocardiography } \\
& \text { THV }=\text { transcatheter heart valve } \\
& \text { VIV }=\text { valve-in-valve }
\end{aligned}
$$

\section{METHODS \\ Patients}

From February 2010 to January 2014, we performed 33 VIV procedures for aortic bioprosthetic degeneration using the Edwards SAPIEN valve (Edwards Lifesciences, Irvine, Calif). Of these 33 patients, $10(30 \%)$ had previously undergone placement of a stentless aortic bioprosthesis: 6 homografts, 1 Toronto SPV (St Jude Medical, St Paul, Minn), 1 Freestyle root (Medtronic Inc, Minneapolis, Minn), 1 O’Brien (Cryolife, Kennesaw, $\mathrm{Ga}$ ), and 1 Pericarbon Freedom stentless valve (Sorin, Saluggia, Italy; Table 1). The mean patient age was $73.3 \pm 14.0$ years (range, $43-90$ ). Of the 10 patients, 7 were men and 3 were women. The mode of presentation was either severe aortic valve regurgitation $(n=7)$ or stenosis $(n=3)$. Six patients presented in New York Heart Association class IV. The mean interval from the previous aortic valve procedure was $14.1 \pm 6.4$ years (range, 7-27). Two patients had undergone $>1$ previous valve replacement. The mean logistic EuroSCORE and Society of Thoracic Surgeons score were calculated. The logistic EuroSCORE was $31.2 \pm 19.0$, and the mean Society of Thoracic Surgeons score was $7.0 \pm 5.2$. The risk of conventional open aortic valve replacement was evaluated by a multidisciplinary team comprised of cardiac surgeons and cardiologists.

\section{Methods}

The preoperative diagnostic workup and routine postoperative care have been previously described in detail. ${ }^{10}$ The previous operative notes were consulted when available to obtain details of the type of valve implanted, valve size, and surgical technique used. A preoperative transesophageal echocardiogram (TEE) was performed in all patients to determine the exact aortic annular diameter. A noncontrast-enhanced computed tomography scan was used to identify and determine the presence of calcification in the aortic annulus. A single valve type, the Edwards SAPIEN heart valve (Edwards Lifesciences), was used in our series. The SAPIEN valve is a balloon expandable THV. We have used all 3 iterations of this device, depending on availability (ie, SAPIEN [steel frame], SAPIEN XT [cobalt chromium frame], and, recently, SAPIEN 3 [cobalt chromium frame]). Depending on the pre- and intraoperative measurements, either a $23-\mathrm{mm}$ or 26-mm device was implanted. The procedures were all performed in a cardiac catheterization laboratory by a combined team of cardiac surgeons, cardiologists, and anesthesiologists. A perfusionist was always present with a primed cardiopulmonary bypass machine. The approach for TAVI was either transfemoral or transapical (TA). The approach chosen was dependent on the team's preference after a review of the preoperative workup findings. The TA approach was preferred when the size of the femoral arteries was not suitable for transfemoral access. In 1 case, a TA approach was preferred because the patient had a previously placed mechanical mitral prosthesis. The techniques for both approaches have been previously described in detail. ${ }^{11,12}$ The size of the new valve to be implanted was determined according to the internal diameter (ID) of the annulus measured using transthoracic echocardiography and intraoperative TEE. In valves other than homografts, the ID of the prosthesis available from published charts was also used as a guide. ${ }^{13} \mathrm{~A}$ size 23-mm SAPIEN valve was used if the ID of the annulus was 18 to
$20 \mathrm{~mm}$, and a 26-mm valve was used for a 22- to 24-mm annulus. In the case of a borderline annulus, such as one with an ID of $21 \mathrm{~mm}$, a larger prosthesis (26-mm SAPIEN) was preferred if the leaflets were not bulky and circumferential annular calcification was minimal. Simultaneous fluoroscopic, angiographic, and TEE imaging was routinely used to guide the precise level for valve deployment. Balloon dilatation of the degenerated valve before insertion of the prosthesis was not undertaken. Slow, gradual inflation of the valve balloon was undertaken in contrast to the rapid valve deployment sometimes seen. Implantation was performed during a short run of ventricular rapid pacing. In 3 cases, a guidewire was placed in the left main stem ostium to provide a landmark during deployment, because it was impossible to determine the correct level of the aortic annulus owing to severe regurgitation (Figure 1, A). Aortography and TEE assessment were used to determine the correct placement and function of the SAPIEN valve immediately after implantation (Figure $1, B$ ). Special attention was also given to the patency of the coronary arteries. The patients were followed up closely postoperatively in accordance with the requirements of our on-site registry. This included patient interviews, clinical examination, and follow-up echocardiography. The complications are presented in accordance with the Valve Academic Research Consortium-2 criteria. ${ }^{14}$

\section{Statistical Analysis}

Continuous variables are presented as the mean \pm standard deviation and dichotomous or nominal variables as numbers and percentages. Student's $t$ test was used to determine statistical significance, with an $\alpha$ of 0.05 for the parametric data set. Statistical analyses were performed using the Statistical Package for Social Sciences, version 17.0, for Windows (SPSS Inc, Chicago, Ill).

\section{RESULTS \\ Operative Course}

Of the 10 patients, 9 required only 1 device implantation, with 1 patient requiring an immediate second SAPIEN implant after low placement of the first valve. The low placement had resulted owing to difficulty visualizing the level of the annulus using angiography because of severe aortic regurgitation (Figure 1, C-E). One intraoperative complication that required an additional procedure. The patient experienced a right ventricular perforation from the transvenous pacing wire used during the procedure. This was immediately diagnosed as pericardial effusion using TEE and was repaired without the use of cardiopulmonary bypass. This happened during a TA procedure in a patient with minimal intrapericardial adhesions. In 5 patients, a SAPIEN size 26-mm valve was implanted and in 5, a size $23-\mathrm{mm}$ valve was implanted. The first-iteration SAPIEN valve was used in 3 patients, the SAPIEN XT in 6 patients, and the SAPIEN 3 in 1 patient. The mean procedure time was $86.7 \pm 27.6$ minutes (range, 44-135). The mean fluoroscopy time was $11.1 \pm 4.7$ minutes (range, 5.5-18). The mean volume of contrast medium used during the procedure was $148 \mathrm{~mL}$ (range, 80-260). After valve implantation, the TEE-measured peak transvalvular gradient had decreased from $33.6 \pm 17.6 \mathrm{~mm} \mathrm{Hg}$ to $11.3 \pm 4.4 \mathrm{~mm} \mathrm{Hg}(P<.05)$. The TEE-measured mean transvalvular gradient had decreased from $16 \pm 9.8 \mathrm{~mm} \mathrm{Hg}$ to $8.0 \pm 4.8 \mathrm{~mm} \mathrm{Hg}$ $(P=.077)$. Of the 10 patients, 4 had grade I paravalvular aortic regurgitation after implantation and 6 had either 
TABLE 1. Stentless valve types and their implantation options

\begin{tabular}{ll}
\hline Valve name and manufacturer & \multicolumn{1}{c}{ Implantation options } \\
\hline Homograft & Full root, mini-root, subcoronary \\
Freestyle (Medtronic) & Full root, mini-root, subcoronary \\
Prima Plus (Edwards Lifesciences) & Full root, mini-root, subcoronary \\
Toronto root (St Jude Medical) & Full root, mini-root \\
Shelhigh Bioconduit (Shelhigh) & Full root \\
Toronto SPV (St Jude Medical) & Subcoronary \\
CryoLife-O'Brien (Cryolife) & Subcoronary \\
Elan (AorTech) & Subcoronary \\
Shelhigh Superstentless (Shelhigh) & Subcoronary \\
Biocor PSB/SJM (St Jude Medical) & Subcoronary \\
Pericarbon Freedom (Sorin) & Subcoronary \\
3F Aortic Bioprosthesis & Subcoronary \\
(3F Therapeutics) & \\
\hline
\end{tabular}

trivial or no regurgitation. No significant changes were seen in the transvavular gradients on the immediate postoperative transthoracic echocardiogram compared with the transthoracic echocardiogram performed at 6 weeks of follow-up. Important details of the procedure are summarized in Table 2.

\section{Postoperative Course}

In the early postoperative course, 3 significant complications developed. One patient required reoperation for venous bleeding from the epicardium after undergoing the procedure by way of the TA approach (BARC type $3 \mathrm{a}$ as per the Valve Academic Research Consortium criteria). A second patient developed transient right-sided weakness, which lasted for 48 hours and resolved completely. A third patient developed acute kidney injury necessitating temporary hemodialysis. No postoperative myocardial infarctions, no indications for postoperative pacemaker insertion, and no wound complications developed. The median intensive care unit length of stay was 1 day (range, $0.5-13$ ), and the median length of hospital stay was 8.5 days (range, 3-44). All patients survived to 30 days. The mean left ventricular ejection fraction was $45.4 \% \pm 14.2 \%$ preoperatively and $42.6 \% \pm 18.5 \%$ at discharge $(P=.77)$. Neither early nor late valve reinterventions or open conversions were required. The mean follow-up was
8.1 months (range, 1-21). At the last follow-up point, all 10 patients were alive.

\section{DISCUSSION}

With an improvement in life expectancy and lower age at which patients opt for a bioprosthetic valve, it is inevitable that an increasing number of patients will present with bioprosthetic valve dysfunction. ${ }^{15}$ The operative mortality for elective redo aortic valve surgery has been reported to range from $2 \%$ to $7 \%$; however, this percentage can increase to $>30 \%$ in high-risk patients. ${ }^{16}$ For this subset of patients, a VIV procedure represents a less invasive alternative to conventional redo surgery. Although a relatively new technology, VIV is now an acceptable treatment in high-risk patients with failed bioprosthetic valves. ${ }^{3-6}$ It is important for the operator to be familiar with the type and characteristics of the failing bioprosthesis for an optimal result. ${ }^{17}$

\section{Bioprosthesis Types}

Essentially, 2 types of bioprosthetic valves are available: stented and stentless. ${ }^{13,18}$ In a stented bioprosthesis, either the frame or sewing ring usually provides fluoroscopic landmarks, which aid during the VIV procedure; also, the frame or sewing ring provides a secure anchor to the THV (Figure 2, $A$ and $B) .{ }^{17}$ Stentless valves, however, are not radiopaque, because they lack a frame and most also lack a distinct sewing ring (Figure 2, $C$ and $D$ ). Furthermore, regurgitation is a common mode of failure. These factors can make the VIV procedure in stentless valves challenging. However, we believe that the fibrosis induced by the sutures used for its implantation will limit the distensibility and can provide anchorage for the VIV. Also, unlike stented valves, in which the presence of the stent frame, sewing ring, and leaflet tissue mounted within the frame effectively reduces the ID available for a VIV procedure, the stentless valves have less effect on the ID and might allow a larger THV implantation compared with a similar-size stented valve. ${ }^{13}$

\section{Stentless Valve Types and Implantation Techniques}

During the past 2 decades, a number of stentless valves have become commercially available worldwide (although
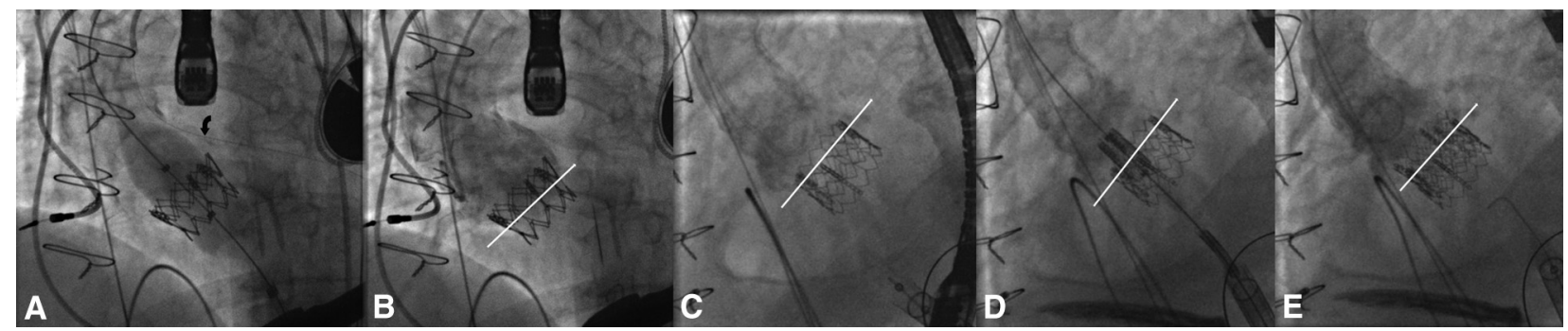

FIGURE 1. SAPIEN valve implantation in stentless valve. White line indicates the annular plane. A, A guide wire was placed in the left main artery (black arrow) to provide a landmark and can provide access to the left main artery. B, Postimplant aortogram after SAPIEN XT implantation. C, SAPIEN valve implanted in a low position. D, Second SAPIEN valve positioned within the first valve. E, Second SAPIEN valve implanted in the correct position. 
TABLE 2. Summary of previous and new valve characteristics

\begin{tabular}{|c|c|c|c|c|c|c|c|}
\hline Pt. no. & $\begin{array}{c}\text { Original } \\
\text { prosthesis type }\end{array}$ & $\begin{array}{c}\text { Interval since } \\
\text { last valve } \\
\text { implant }(y) \\
\end{array}$ & Size $(\mathbf{m m})$ & $\begin{array}{c}\text { Pathologic } \\
\text { type }\end{array}$ & $\begin{array}{c}\text { SAPIEN } \\
\text { valve size }(\mathbf{m m}) \\
\end{array}$ & $\begin{array}{l}\text { Postimplant aortic } \\
\text { regurgitation }\end{array}$ & Complications \\
\hline 1 & Homograft & 15.3 & 26 & AS & 26, SAPIEN & None & Second SAPIEN implant \\
\hline 2 & O'Brien Cryolife & 17.3 & 23 & AR & 23, SAPIEN & Trivial & Acute renal failure \\
\hline 3 & Homograft & 13.3 & 26 & AS & 26, SAPIEN & Trivial & Bleeding \\
\hline 4 & Homograft & 27.3 & 24 & $\mathrm{AR}$ & 23, SAPIEN XT & Mild & None \\
\hline 5 & Sorin Pericarbon stentless & 6.6 & 23 & & 23, SAPIEN XT & Trivial & $\begin{array}{l}\text { Right ventricular tear repaired } \\
\text { on-table }\end{array}$ \\
\hline 6 & Homograft & 14.3 & 28 & AR & 26, SAPIEN XT & Mild & None \\
\hline 7 & St Jude Toronto SPV root & 9.7 & 25 & AS & 26, SAPIEN XT & Mild & $\begin{array}{l}\text { Transient neurologic deficit } \\
\text { postoperatively }\end{array}$ \\
\hline 8 & Homograft & 9.3 & 22 & $\mathrm{AR}$ & 23, SAPIEN XT & Trivial & None \\
\hline 9 & Freestyle Root & 7 & 23 & $\mathrm{AR}$ & 23, SAPIEN XT & Trivial & None \\
\hline 10 & Homograft & 16 & 26 & AR & 26, SAPIEN 3 & Mild & None \\
\hline
\end{tabular}

Pt. no., Patient number; $A S$, aortic stenosis; $A R$, aortic regurgitation.

some have since been withdrawn from the market), and each has specific recommendations regarding implantation options (Table 1).

Unlike stented valves, stentless valves can be implanted using 1 of 3 techniques:

1. Subcoronary implantation (Figure 3, A)

2. Full root replacement (Figure $3, B$ )

3. Mini-root or inclusion technique (Figure 3,C).

From the perspective of performing a VIV TAVI, it is essential to confirm the method of implantation, because the choice can influence the risks and success, as discussed in the following sections.

\section{Risk of Coronary Obstruction}

Coronary obstruction is an uncommon, but well-known, complication after a VIV procedure. ${ }^{19}$ The risk is substantially greater for stentless valves than for stented valves. ${ }^{9,19}$ This is related to the valve design. In most stented valves, the leaflets will be sutured within the stent frame; hence, even when pushed out with a THV, a gap will be present between them and the coronary ostia (Figure 4, A). In the subcoronary and mini-root techniques, the suture line will be in close proximity to the coronary ostia. With no stent frame present, the chance of coronary obstruction is greater after VIV, because the leaflets can be easily pushed to block the coronary ostia (Figure 4, $B$ ). In contrast, during full root replacement, the site of implantation of the coronary buttons will vary; however, essentially, the end result will mimic a native aortic root, which could reduce the chance of coronary obstruction after a VIV procedure (Figure 4,C).

The proximity of the suture line to the coronary ostia and bulky calcified leaflets should alert the operator. The former can be confirmed by aortography and later by echocardiography. If the risk is anticipated to be high, it would be wise to place a guidewire in the coronary ostia, such as in 2 of our cases, and also to prepare the cardiopulmonary bypass circuit. One can use balloon aortic valvuloplasty with aortic root contrast injection to diagnose this problem before proceeding to THV implantation.

\section{THV Sizing and THV Type}

Valve embolization has also been reported with greater frequency with stentless valves than with stented valves. ${ }^{9}$ A part of the problem is assessing the true ID of the stentless valves. Unlike the stented valves, in which the geometry and dimensions of the valve are maintained after implantation and, hence, the ID and true ID can be obtained from published charts, the final dimensions of the stentless valves can vary, depending on the native root dimensions and

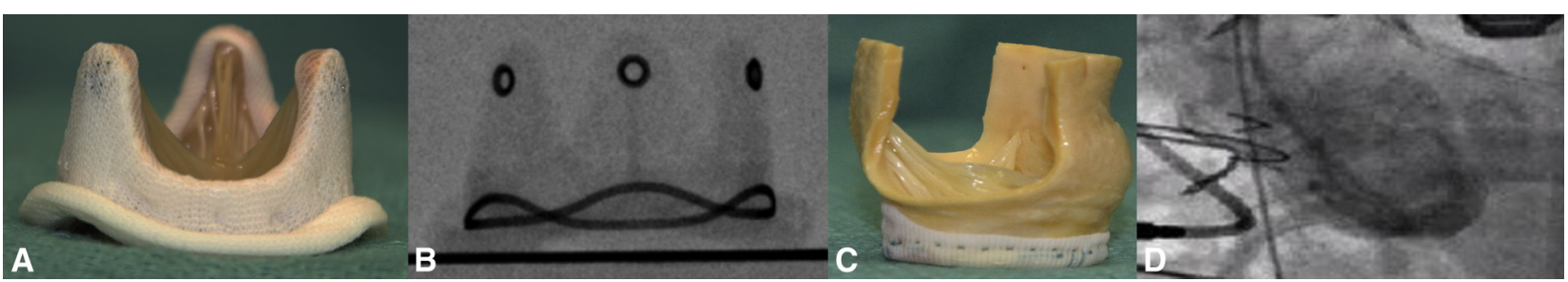

FIGURE 2. Types of bioprosthetic aortic valves. A, Stented valve example (Hancock 2) demonstrating its structure. B, Stentless valve example demonstrating the fluoroscopic appearance. C, Stentless valve example (Freestyle valve) demonstrating its structure. D, Stentless valve example (Freestyle valve) demonstrating radiolucent characteristics. 


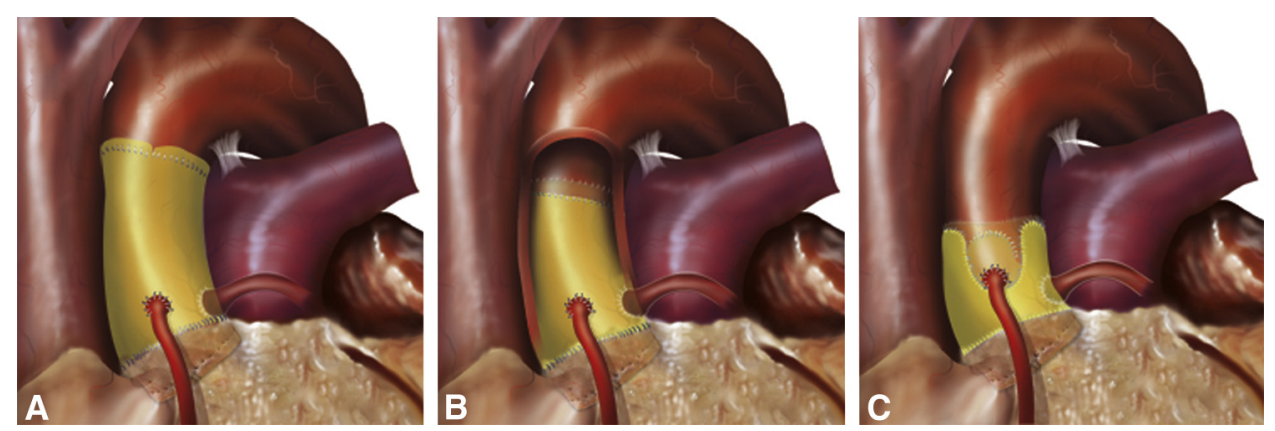

FIGURE 3. Types of stentless valves and techniques of implantation. A, Subcoronary implantation. B, Full root implantation. C, Mini-root implantation.

method of implantation. The ID and true ID of the stentless roots can be used as a reference, but the final ID of stentless valves will be influenced by the suturing technique and diameter of the native root in which it is implanted. Homografts have historically been one of the most frequently used stentless valves. Sizing of the homograft has never been standardized and after implantation can vary from the initial size. Hence, it is best to compliment these measurements with computed tomography or 3-dimensional TEE. We based our final decision on sizing intraoperatively using 3-dimensional TEE. ${ }^{20}$

The THV is anchored by virtue of oversizing. ${ }^{1,2}$ Unlike when performing TAVI in the case of a native calcified aortic valve or stented bioprosthesis, we erred on the side of greater oversizing than usual. We believe this was essential and safer in this setting for the following 3 reasons. First, the chance of coronary obstruction was less than in a native valve case, because regurgitation and torn leaflets were the major etiologies of failure. Second, the risk of annular disruption was less. Finally, more secure anchoring could be obtained. Hence, a 23-mm SAPIEN valve was used for an aortic annulus diameter of 18 to 20 $\mathrm{mm}$ and a $26-\mathrm{mm}$ valve for a $22-$ to $24-\mathrm{mm}$ annulus. In the case of a borderline annulus, such as $21 \mathrm{~mm}$, a larger prosthesis (26-mm SAPIEN) was preferred if the leaflets were not bulky and circumferential annular calcification was minimal. We believe that this degree of "oversizing" was essential to achieve secure anchoring of the device and was a key factor contributing to the technical success of the procedure in those patients with primary aortic regurgitation.

Both balloon and self-expandable THVs have been used to treat stentless valves and opinion might favor nitinolbased devices. ${ }^{3,6,9}$ However, this has no scientific basis, and we have exclusively used balloon expanded THVs. As mentioned, stentless valves can function similar to a native aortic valve but still have bulk, suture line, and calcification sufficient to provide an anchor for any THV. However, future valve designs with which one can implant, check coronary flow, and, if necessary, retrieve might be more suitable for this indication.

\section{Prosthesis Positioning}

Once again, the incidence of malpositioning and related complications has been much greater during VIV procedures with a stentless valve. ${ }^{6,9}$ The absence of fluoroscopic markers and aortic regurgitation, when present, can make it difficult to identify the annular plane. In our first patient, we deployed the valve low, because we were using a rapid inflation technique at that time and did not use coronary wires. To maximize precise deployment, we now routinely perform slow and gradual
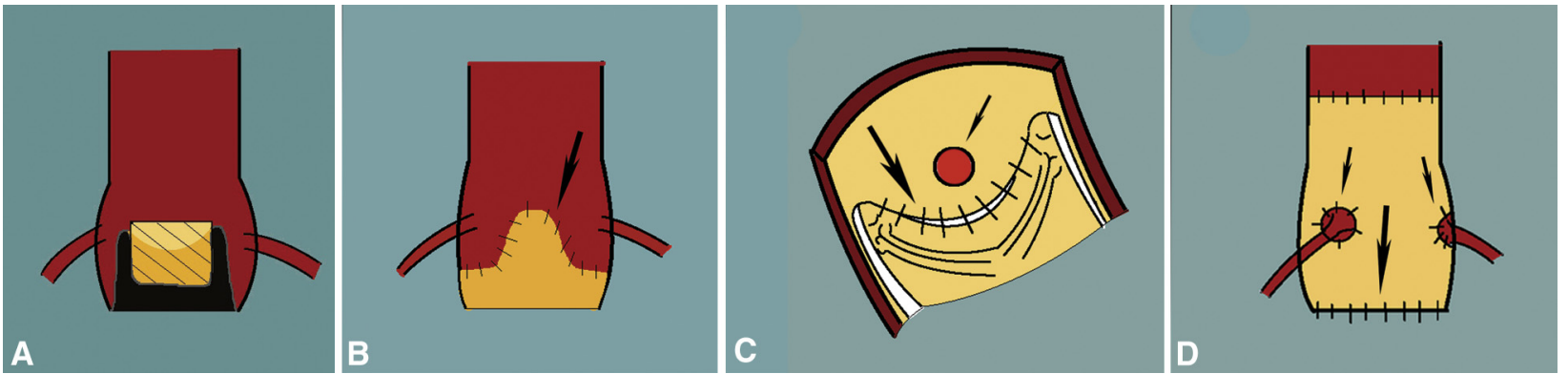

FIGURE 4. Relationship of coronary ostia and bioprosthesis. A, Stented valve. B, Stentless valve replaced as subcoronary implantation (arrow points to suture line). C, Cross-section of stentless valve subcoronary implantation demonstrating proximity of the suture line (large arrow) and coronary ostia (small arrow). D, Stentless valve replaced as full root, with suture line (large arrow) at the level of annulus and the coronary ostia have been reimplanted higher up (small arrow). 
inflation of the prosthesis (vs forced and rapid inflation) during a single short phase of rapid ventricular pacing. At the same time, we also perform continuous contrast injection at the level of the aortic root until the prosthesis has been at least half deployed. We have also found that placing a guidewire in left main or right coronary artery (Figure 1, $A$ ) has occasionally been invaluable (3 cases in our series) in providing us with a landmark for valve deployment. This has been particularly useful in cases in which severe aortic regurgitation precluded us from obtaining a satisfactory root angiogram and/or we had difficulties in obtaining good views of the annulus using TEE.

\section{Other Technical Considerations}

First, the surgical details of the bioprosthesis such as the valve type and size and method of implantation should be obtained because they are of paramount importance for reasons we have highlighted.

Second, it is essential to rule out infective endocarditis in any patient presenting with aortic regurgitation in the setting of a previously placed stentless aortic valve. It should not be assumed that the cause of the regurgitation is primary leaflet degeneration.

Third, we do not routinely perform balloon aortic valvuloplasty of the degenerated valve before insertion of the prosthesis unless the possibility of coronary obstruction is a very great.

Finally, we believe that the surgical approach for access should be highly individualized after a thorough review of the preoperative clinical examination and radiographic investigation (which includes a full computed tomography aortogram at our center) findings. In the present series, we performed the procedure using either a transfemoral or TA approach. However, transaortic access has also been used for the VIV procedure. ${ }^{21}$

\section{CONCLUSIONS}

We have demonstrated that the TAVI procedure after previous stentless aortic valve replacement and that the valve-in-stentless-valve concept is technically feasible and safe using a balloon expandable SAPIEN THV. The early results showed improvement in hemodynamics and symptom amelioration. Larger studies with longer followup are needed to confirm our results.

\section{References}

1. Cribier A, Eltchaninoff H, Bash A, Borenstein N, Tron C, Bauer F, et al. Percutaneous transcatheter implantation of an aortic valve prosthesis for calcific aortic stenosis: first human case description. Circulation. 2002;106:3006-8.

2. Leon MB, Smith CR, Mack M, Miller DC, Moses MW, Svensson LG, et al. Transcatheter aortic valve implantation for aortic stenosis in patients who cannot undergo surgery. N Engl J Med. 2010;363:1597-607.

3. Bapat V, Attia R, Redwood S, Hancock J, Wislon K, Young C, et al. Use of transcatheter heart valves for a valve-in-valve implantation in patients with degenerated aortic bioprosthesis: technical considerations and results. $J$ Thorac Cardiovsc Surg. 2012;144:1372-9.
4. Pasic M, Unbehaun A, Dreysse S, Buz S, Drews T, Kukucha M, et al. Transapical aortic valve implantation after previous aortic valve replacement: clinical proof of the "valve-in-valve" concept. J Thorac Cardiovasc Surg. 2011;142:270-7.

5. Mylotte D, Lange R, Martucci G, Piazza N. Transcatheter heart valve implantation for failing surgical bioprostheses: technical considerations and evidence for valve-in-valve procedures. Heart. 2013;99:960-7.

6. Piazza N, Bleiziffer S, Brockmann G, Hendrick R, Deutsch M, Optiz A, et al. Transcatheter aortic valve implantation for failing surgical bioprosthetic valve: from concept to clinical application and evaluation (part 2). JACC Cardiovasc Interv. 2011;4:733-42.

7. Barratt-Boyes BG, Christie GW, Raudkivi PJ. The stentless bioprosthesis: surgical challenges and implications for long-term durability. Eur J Cardiothorac Surg. 1992;6:S39-42.

8. Sarkar K, Ussia GP, Tamburino C. Transcatheter aortic valve implantation for severe aortic regurgitation in a stentless bioprosthetic valve with the Core Valve revalving system-technical tips and role of the Accutrak system. Catheter Cardiovasc Interv. 2011;78:485-90.

9. Dvir D, Webb J, Brecker S, Bleiziffer S, Hildick-Smith D, Colombo A, et al. Transcatheter aortic valve replacement for degenerative bioprosthetic surgical valves: results from the global valve-in-valve registry. Circulation. 2012;126:2335-44.

10. Vahanian A, Alfieri O, Al-Attar N, Antunes MJ, Bax J, Cormier B, et al. Transcatheter valve implantation for patients with aortic stenosis: a position statement from the European Association of Cardio-Thoracic Surgery (EACTS) and the European Society of Cardiology (ESC), in collaboration with the European Association of Percutaneous Cardiovascular Interventions (EAPCI). Eur Heart J. 2008;29:1463-70.

11. Pasic M, Buz S, Dreysse S, Drews T, Unbehaun A, Klein C, et al. Transapical aortic valve implantation in 194 patients: problems, complications, and solutions. Ann Thorac Surg. 2010;90:1463-70.

12. Bleiziffer S, Ruge H, Mazzitelli D, Hutter A, Optiz A, Bauernschmitt R, et al. Survival after transapical and transfemoral aortic valve implantation: talking about two different patient populations. J Thorac Cardiovasc Surg. 2009;138:1073-80.

13. Bapat VN, Attia R, Thomas M. Effect of valve design on the stent internal diameter of a bioprosthetic valve: a concept of true internal diameter and its implications for the valve-in-valve procedure. JACC Cardiovasc Interv. 2014;7:115-27.

14. Kappetein AP, Head SJ, Généreux P, Piazza N, van Mieghem NM, Blackstone EH, et al. Updated standardized endpoint definitions for transcatheter aortic valve implantation: the Valve Academic Research Consortium-2 consensus document. J Am Coll Cardiol. 2012;60:1438-54.

15. Niclauss L, von Segesser LK, Ferrari E. Aortic biological valve prosthesis in patients younger than 65 years of age: transition to a flexible age limit? Interact Cardiovasc Thorac Surg. 2013;16:501-7.

16. Chikwe J, Filsoufi F, Carpentier AF. Prosthetic valve selection for middle-aged patients with aortic stenosis. Nat Rev Cardiol. 2010;7:711-9.

17. Bapat VN, Mydin I, Chadalavada S, Tehrani H, Attia R, Thomas M. A guide to fluoroscopic identification and design of bioprosthetic valves: a reference for valve-in-valve procedure. Catheter Cardiovasc Interv. 2013;81:853-61.

18. Piazza N, Bleiziffer S, Brockmann G, Hendrick R, Deutsch M, Optiz A, et al. Transcatheter aortic valve implantation for failing surgical aortic bioprosthetic valve: from concept to clinical application and evaluation (part 1). JACC Cardiovasc Interv. 2011;4:721-32.

19. Urena M, Nombela-Franco L, Doyle D, De Larochellière R, Dumont E, Villeneuve J, et al. Transcatheter aortic valve implantation for the treatment of surgical valve dysfunction ("valve-in-valve"): assessing the risk of coronary obstruction. J Card Surg. 2012;27:682-5.

20. Husser O, Holzamer A, Resch M, Endemann DH, Nunez J, Bodi V, et al. Prosthesis sizing for transcatheter aortic valve implantation-comparison of three dimensional transesophageal echocardiography with multislice computed tomography. Int J Cardiol. 2013;168:3431-8.

21. Thlberg L, Sahlman A, Sinisalo J, Rapola J, Laine M. Transaortic valve-in-valve implantation after previous aortic root homograft. Ann Thorac Surg. 2012;94: 1718-21.

\section{Discussion}

Dr A. Pieter Kappetein (Rotterdam, The Netherlands). Dr Bapat, congratulations on a great report, and again, it is another excellent contribution from your group for a very complex patient population. 
The valve that you implanted actually concerns a variety of bioprostheses, 6 homografts, 1 Toronto valve, 1 Freestyle valve, 1 O'Brien valve, and 1 Pericarbon valve, and the mean age of those patients was 73 years. The mean interval from the previous aortic valve procedure to the implantation of the bioprosthesis or homograft was 14 years, but it concerns a wide range, from 7 years to 27 years. The groups were rather small; thus, I assume you could not determine a difference between the homografts and xenografts, but perhaps you could.

Now that VIV procedures are possible, we will see much larger series of patients with a failing bioprosthesis. If you ask the average surgeon how many failing bioprostheses they operate on per year, they will probably say 1 or 2 or 3 , depending on the size of their practice. Last year at EuroPCR, a series was presented of 450 patients with a failing bioprosthesis, and the mean interval between implantation of the bioprosthesis and the VIV procedure was only 9 years. If we study our surgical data, we often see series with a follow-up period of $\leq 20$ years and $\leq 95 \%$ freedom from reoperation.

So, the question is, what is the reason that we have always believed that bioprosthetic valves can last $\leq 20$ years and that now we actually see large series of patients undergoing a VIV procedure at a relatively low average age, as you pointed out, 73 years, but also, that the interval between implantation of the bioprosthesis and the VIV procedure is not as long as 20 years? Do you think it is justified, to lower the age at which we implant a bioprosthesis now that we have the possibility of a VIV procedure?

My last question, do you think that one of the other transcatheter prostheses, for example a self-expandable valve, might have an advantage, with a lower risk of coronary obstruction?

Thank you very much again for an excellent presentation.

Dr Bapat. Thank you very much, Dr Kappetein, for your excellent questions.

I think my view is that the reason we are seeing early failure rates or less durability data in terms of duration is because we are implanting them in younger patients. I think the series that showed that the durability of the valves would be 20 years or so was more historical in which the implantation age for a bioprosthesis was 70 plus years.

Today, in most of my practice, I rarely implant a mechanical valve because even a patient of 50 years requests a tissue valve. That might explain why we are seeing patients returning slightly earlier than in the past.

Dr Kappetein. If I could interrupt. If one implants a bioprosthesis in a 50-year-old patient, and the mean follow-up for freedom from reoperation is 15 years, one will need to do a VIV procedure in a 65-year-old patient. For the transcatheter heart valves, we do not know the durability in a 65 -year-old patient, and, if the valve lasts, for example, 10 years, one will have a 75 -year-old patient in whom you need to perform a valve in a valve in a valve procedure.

Dr Bapat. I think that is a very good question, and I tend to match, or my group tends to match, the life expectancy of the patient to the treatment. My view regarding such patients, the specific example you gave, would be to reoperate in the patient at 65 years and then perform a VIV at age 75 or 80 years when he comes, if he survives to that age, rather than perform a VIV procedure at 65 years and then reoperate when he is 80 years old. However if his life expectancy is shorter because of comorbidities, I think it would be a reasonable to perform a VIV procedure at age 65 years.

So, I think we need to match the patient's survival to the type of treatment we have, and that has been our view at present.

Dr Kappetein. Right.

Dr Bapat. Regarding your third question, which is other devices, yes, a nitinol platform or valves such as the CoreValve and Portico would definitely have some advantage because they are self expandable and hence have been favored for scentless valves.

However, I think positioning a nitinol self-expanding valve becomes very tricky because these are longer devices. Also, with aortic regurgitation, you might not achieve accurate landing in contrast to a balloon expandable valve, because most balloon expandable valves are implanted under pacing.

The main reason we presented our report was because of the fear that a balloon expandable valve needs a lot of anchor, such as calcium, and might not be suitable for stentless valves at all. However, I think the fibrosis and suture material provides enough anchor to implant these valves.

Dr Kappetein. Thank you very much. Do you think that most of our knowledge of the durability of bioprosthesis is based on reoperation-free data and not freedom from valve failure, which are 2 distinct entities.

My impression has been that we see more patients with a failing bioprosthesis because we have the possibility of a VIV with transcatheter heart valve implantation. We might have overestimated the durability of our bioprosthetic valves.

Dr Bapat. I think I completely agree with you.

Dr Kappetein. Okay. Thank you very much.

Dr Danny Dvir (Vancouver, British Columbia, Canada). Yes. Dr Kappetein, we were very surprised in the global registry to see that the median interval to failure between surgery and the VIV procedure was only 9 years. We were really in shock when we saw that finding.

The stentless valves do fail, just as you showed, Dr Bapat, really longer than the stented, 12 to 13 years versus 8 to 9 years. However, I must say that when we are talking about decreasing the cutoff age between implantation of a mechanical valve to bioprosthetic valve, thinking of performing a VIV procedure in the future, we must understand that some limitations exist to the VIV field. We have the left main obstruction, the malpositioning, and, probably the most problematic, the elevated postprocedure gradients.

So when we are talking about implantation of a bioprosthetic valve, thinking of performing a VIV procedure in the future, we should understand that the surgical procedure has a great amount of impact and influence on the success of performing VIV in the future. The surgical valve size has a great amount of impact. The position of the coronaries, the relationship between the surgical valve and the coronaries, will have a great amount of impact, as will the type of the surgical valve.

Dr Bapat. I think what I must point out, Dr Kappetein, is that these are a very high-risk select group of patients that have undergone the VIV procedure. Fit patients who were at medium risk and, relatively, even at high risk, have undergone open surgery.

Dr Hans-Joachim Schäfers (Homburg/Saar, Germany). Perhaps just 1 quick question from me and a short answer. 
The youngest patient in your group was 43 years old. Given the known uncertainty about the durability of these transcatheter valves, what should be the lowest age at which we would seriously consider transcatheter replacement?

Dr Bapat. I think you should consider, for example, in a young woman who wants to have children, and she does not want to take anticoagulation. I would implant a transcatheter valve, let her complete her family, and then reoperate.

Dr Schäfers. Otherwise? That is a special situation. Otherwise?

Dr Bapat. If we think that the life expectancy of the patient will be less than the durability of the transcatheter valve, we would implant a transcatheter valve even in younger patients. 